\title{
O PROJETO "DIREITOS HUMANOS NA PRÁTICA" NO MONITORAMENTO DE GARANTIAS DE ADOLESCENTES EM MEDIDA SOCIOEDUCATIVA DE INTERNAÇÃO NO CEDUC/MOSSORÓ
}

\author{
Ana Carolina Mota Souto \\ anamotasouto@gmail.com \\ Universidade Federal Rural do Semiárido - UFERSA
}

\section{RESUMO}

Este artigo foi motivado por reflexões sobre a atuação dos autores no Projeto de Extensão "Direitos Humanos na Prática”, vinculado à Universidade Federal Rural do Semiárido. 0 objetivo do trabalho consiste na compreensão da importância do projeto no monitoramento de garantias dos adolescentes em medida socioeducativa de internação no CEDUC/Mossoró, tendo em vista o difícil contexto sociofamiliar de adolescentes envolvidos com atos ilícitos e em cumprimento de medida de privação de liberdade, somada à carência das unidades de socioeducação do país e da defensoria pública para uma defesa técnica mais efetiva. Para tanto, o trabalho apresenta um pouco do cenário do sistema socioeducativo do Rio Grande do Norte, esclarecendo como se processa a medida de internação. A metodologia aplicada foi descritiva, com uma abordagem de pesquisa qualitativa. Como resultado, pode-se constatar a relevância do referido projeto de extensão para colaborar com a garantia de direitos dos adolescentes, por meio de suporte à defesa dos jovens e à própria unidade de socioeducação.

PALAVRAS-CHAVE: Medida socioeducativa; Internação; Adolescente.

\section{INTRODUÇÃO}

Para perceber a importância do projeto de extensão "Direitos Humanos na Prática" no monitoramento das garantias dos adolescentes em medida socioeducativa de internação no CEDUC/Mossoró, é necessário, a priori, destacar que medidas socioeducativas são aquelas que devem ser aplicadas quando for observada a prática de ato infracional. Esse contexto de adolescentes envolvidos com atos infracionais, somado ao panorama de violação dos direitos humanos e às experiências vivenciadas na atuação extensionista, evidencia a necessidade de compreensão do sistema socioeducativo, assim como dos adolescentes internados, por uma outra perspectiva, considerando o espaço socioeducativo como significativo, mas esquecido por grande parte da sociedade. 
Nesse sentido, o presente trabalho abordará experiências vivenciadas na extensão universitária na supracitada unidade de socioeducação do Estado do Rio Grande do Norte, no intuito de partilhar com a comunidade acadêmica as contribuições desta ação, no sentido de monitoramento da política pública de atendimento socioeducativo. 0 recorte não despreza o reconhecimento das contribuições, em termos de ganhos pedagógicos e de formação acadêmicoprofissional, aos discentes envolvidos nesta comunicação/interação socioinstitucional. Todavia, o foco será o acompanhamento que a extensão realiza da execução da política pública, assemelhando-se a um controle social da atuação estatal, ao mesmo tempo em que colabora e coopera com os serviços prestados pela Unidade. Para atingir este objetivo, o conteúdo do trabalho descreverá como o projeto de extensão se desenvolve nesta seara, apresentando também conceitos legais básicos sobre a matéria.

\section{MEDIDAS SOCIOEDUCATIVAS E O PROJETO DE EXTENSÃO "DIREITOS HUMANOS NA PRÁTICA"}

As medidas socioeducativas são regulamentadas no Estatuto da Criança e do Adolescente (ECA - Lei n. ${ }^{\circ}$ 8.069/90) e na Lei $n^{\circ}$ 12.594/2012 (Lei do Sistema Nacional de Atendimento Socioeducativo - SINASE). Nesse caso, tais legislações dispõem sobre todos os direitos e garantias dos adolescentes em cumprimento de medida. A atuação do Projeto de Extensão no monitoramento dessas garantias é um desdobramento lógico da atuação universitária que se volta ao diálogo com os sujeitos privados de liberdade, prestando-lhe atenção interdisciplinar (com extensionistas em formação em diversos cursos, como Direito, Serviço Social, Psicologia e Pedagogia). No momento em que a extensão interage com os espaços, termina por exercer a tarefa cidadã de controle social da política pública com a qual coopera.

O dito "controle social" exercido pelo Projeto não se pretende enquadrar nas previsões legais e oficiais de controle realizado pelos conselhos (como os Conselhos de Direitos da Criança e do Adolescente, previstos no art. 70-A, II, do ECA), todavia, se caracteriza como participação política, definida por Dallari (2010, p. 28), como "dever moral de todos os indivíduos e uma necessidade fundamental da natureza humana". Enquanto grupo, o Projeto se configura como expressão de participação coletiva com potencial para produzir alguma influência na política pública monitorada.

0 modo de execução do Projeto não deixa de ser uma concretização da previsão do art. 21, da Declaração Universal dos Direitos Humanos de 1948, de que "toda a pessoa tem o direito de tomar parte na direção dos negócios públicos do seu país". Contudo, o controle social não se restringe às modalidades previstas em lei, especialmente, se considerarmos que os processos de democratização sempre contaram com protagonismos de movimentos - muitas vezes estudantis (PATEMAN, 1992) - que se articulam até contra a oficialidade estatal, bem como é importante levar em conta que os grupos de pressão sobre os executores das políticas atuam não 
apenas com instrumentos formais previstos expressamente nas normas. No caso da extensão, o papel social da universidade autoriza o exercício de diálogo interinstitucional e comunitário, que culmina uma espécie de controle social pelo monitoramento decorrente da interação nos espaços socioeducativos.

Maria da Glória Gohn (2011, p. 356), após analisar conselhos e fóruns como exemplos de participação da sociedade civil na gestão das políticas públicas, como formas de exercício de controle social sobre a atividade do Estado, aponta para a necessidade de "novas práticas" que reflitam "um novo tecido social, denso e diversificado", superando formas tradicionais de fazer política, buscando "alternativas democráticas, novas possibilidades concretas para o futuro". Nesse sentido, entendemos que as atividades extensionistas se revelam como possibilidades de atuação destas inovadoras ações cidadãs.

Ainda, é importante o alerta de Tiago Martinelli de que há necessidade de reconhecer que há disputas e lutas para se avançar no direito à participação democrática no campo das políticas públicas. Por tal razão, ele distingue uma "concepção assistencialista do controle social" e a "efetivação do controle em uma perspectiva democrática". Para o citado autor, a primeira modalidade gera ações motivadas por uma lógica de caridade e de disputa por recursos públicos, além do "clientelismo e a subalternização dos sujeitos de direito". Por outro lado, a perspectiva democrática vislumbra o controle social pela atuação da sociedade sobre o Estado e não, como uma visão durkheimiana sugere, o controle do Estado sobre os indivíduos (MARTINELLI, 2014. p. 246).

No cenário da extensão, como desenvolvimento da autonomia universitária, os riscos de uma atuação não emancipatória dos cidadãos (extensionistas) e do público (sujeitos dos direitos monitorados - adolescentes em conflito com a lei) restam reduzidos, se considerarmos a horizontalidade da relação entre estudantes e socioeducandos, além da ausência de subordinação do projeto aos gestores estaduais ou municipais responsáveis pelas políticas de atendimento socioeducativo.

O controle social tem sua concepção advinda da Constituição Federal de 1988, enquanto instrumento de efetivação da participação popular no processo de gestão político-administrativafinanceira e técnico-operativa, com caráter democrático e descentralizado. Dentro dessa lógica, o controle do Estado é exercido pela sociedade na garantia dos direitos fundamentais e dos princípios democráticos balizados nos preceitos constitucionais.

O Fórum Permanente das ONGs de Defesa dos Direitos da Criança e do Adolescente do Ceará $(2011$, p. 6) lançou o documento "Monitoramento do sistema socioeducativo: diagnóstico da privação de liberdade de adolescentes no Ceará", no qual afirma que, no intuito de garantir a efetivação dos direitos elencados no ECA, realiza "controle social das políticas públicas voltadas ao atendimento do adolescente a quem se atribui autoria de ato infracional". Logo, atuar na garantia de direitos exige da extensão monitorar e, portanto, exercer o controle social, em alguma medida, do atendimento socioeducativo.

Instituído em 2012 e com abrangência em todo o território brasileiro, o Sistema Nacional de Atendimento Socioeducativo (SINASE) é a política pública que regulamenta e coordena a 
execução de medidas socioeducativas destinadas a adolescentes autores de ato infracional. Essa faz parte de uma estrutura integrada que busca articular os sistemas estaduais, distrital e municipais. Tal sistema tem como principal objetivo desenvolver uma ação socioeducativa sustentada no respeito aos direitos humanos.

Entre as medidas socioeducativas (advertência; obrigação de reparar o dano; prestação de serviços à comunidade; liberdade assistida; semiliberdade; internação em estabelecimento educacional) considera-se mais grave a internação, pois nesta o indivíduo é privado de sua liberdade e vida social por prazo indeterminado - mas não superior à três anos - e é destinada a adolescentes que cometeram grave ameaça ou violência a pessoa, por reincidência no cometimento de outros atos graves ou reiterado descumprimento de medida previamente imposta.

O Estatuto da Criança e do Adolescente prevê esta sanção, mas não se desconsidera a condição peculiar de desenvolvimento dos adolescentes, pelo que a internação deve observar os princípios da brevidade e da excepcionalidade. Não obstante, como assevera Moreira (2011, p. 10), há uma premente necessidade de cessar com essa cultura da "internação violenta" e agregar a possibilidade de um tratamento que busque mudar o contexto de violação de direitos, além de garantir uma verdadeira educação social para esses adolescentes.

Recentemente, no ano de 2015, em âmbito estadual, foi instituído o Regimento Interno das Unidades de Atendimento ao Adolescente em cumprimento de medida socioeducativa de Internação e Semiliberdade (Portaria $n^{\circ}$ 270/15-GP da FUNDAC), o qual reconhece, em seu art. $4^{\circ}$ que "A medida socioeducativa tem natureza sancionatória e conteúdo prevalentemente pedagógico" (RIO GRANDE DO NORTE, 2015). Assim, é relevante destacar que o cumprimento das medidas, além de procurar responsabilizar e desaprovar a conduta do adolescente, objetiva a sua (re)integração social por meio de processos educacionais.

Isto posto, subtende-se que, como toda pessoa humana, os adolescentes privados de liberdade também são detentores de direitos e garantias. Entre estes, o direito ao esclarecimento da sua situação processual, previsto no art. 94, inciso XV, do ECA ("informar, periodicamente, o adolescente internado sobre sua situação processual"). Diante da inexistência de profissionais na Unidade para prestar tais informações e da carência da defensoria pública para atender a demanda, o projeto de extensão "Direitos Humanos na Prática" fez desta ação um dos seus objetivos.

Assim, são realizadas reuniões semanais entre extensionistas e professores para, em conjunto, estudarem textos referentes à matéria, planejar novas ações e avaliar as que já foram efetuadas. Vale salientar que o Projeto, neste momento, atua em três eixos diferentes, dois destes no ambiente socioeducativo. A atuação no CEDUC/Mossoró faz parte do eixo I de atuação. Dessa forma, são realizadas, em média, cinco visitas por mês à Instituição, sendo oferecida uma assistência interdisciplinar aos adolescentes a partir do diálogo destes com os extensionistas dos cursos de Direito, Serviço Social, Psicologia e Pedagogia. Antes de cada reunião com os jovens, a equipe do Projeto de Extensão tem acesso ao processo judicial de execução da medida 
socioeducativa, autorizado pela Vara da Infância e Juventude da Comarca de Mossoró. Feito o estudo do processo judicial e do Plano Individual de Atendimento (PIA) de cada adolescente, documento elaborado pela equipe técnica da Unidade (CEDUC/Mossoró), são agendadas as visitas à Unidade para conversa reservada com cada adolescente.

Nos encontros com os socioeducandos, são transmitidas as informações processuais obtidas e esclarecidas dúvidas que os adolescentes tiverem, bem como se orienta a respeito da audiência judicial de reavaliação da medida socioeducativa. Neste instante, também se aplica um instrumento individual de coleta de dados criado pelos integrantes do projeto, por meio do qual são abordados os aspectos jurídicos do processo; os traços psicossociais do adolescente e os ambientes em que está ou esteve inserido; além da perspectiva pedagógica sobre a sua vida dentro e fora da Unidade. Por meio desses diálogos, são obtidos relatos acerca da execução da medida na Unidade e tais narrativas contribuem para o monitoramento das garantias daqueles que lá estão.

Com o instrumento de coleta de cada adolescente, ainda é possível dispor de um banco de dados para eventuais dúvidas sobre o socioeducando ou trabalhos e pesquisas a serem desenvolvidos pelos extensionistas, compartilhando a realidade, com ética e respeito aos sujeitos. Sendo necessário frisar que o instrumento de coleta é baseado em direitos previstos nas legislações supracitadas, mas sem indicadores objetivos para fornecer à gestão de forma sistemática. Além disso, esse documento de coleta contribui para a elaboração dos relatórios sobre a visita - que são entregues à juíza da Vara da Infância e Juventude da Comarca de Mossoró, parceira do projeto. Assim, com esse compartilhamento, os relatórios são anexados ao processo e tornam-se acessíveis aos servidores da FUNDAC e aos membros do Ministério Público que possuem funções institucionais de garantias de direitos dos adolescentes. Em tais relatórios, são abordados aspectos da internação do adolescente, sua vida familiar e afetiva, percepções sobre o ato cometido, amizades e inimizades, perspectivas de futuro, reinvindicações quanto à Unidade de internação, entre outros tópicos variáveis de acordo com o interesse e abertura do adolescente para adentrar em certos assuntos.

Essa atividade se mostra relevante a medida que observamos a explanação de Castro e Guareschi $(2008$, p. 206) sobre a necessidade de um contexto de crítica ao sistema de atendimento e de justiça para adolescentes que cometem ato infracional. Destacando-se a conveniência em tratar cada indivíduo e sua trajetória de vida com "respeito à singularidade". Assim, visando permitir que os adolescentes passem a "se reconhecerem por outros modos de ser e estar no mundo" cabe, na atuação, o enfoque em outros atributos que não o cometimento do ato.

Em vista disso, a atuação do projeto se coaduna com a visão exposta por Giustina, Kolody, Moss, e Poli (2014, p. 8), quando afirmam que a extensão universitária contribui para o controle social de políticas públicas, sendo um dos caminhos para relacionar Estado e sociedade civil, de modo que "o desenvolvimento das ações do projeto de extensão é importante para fortalecer as práticas de controle social democrático, ampliar a democratização dos espaços públicos, intensificar as relações entre Universidade Pública e demandas da comunidade". Dessa forma, 
por meio da prestação de serviço (informação processual e orientação jurídica), o projeto oferece diálogo interprofissional para captar demandas dos adolescentes e levar aos órgãos e agentes competentes, monitorando a garantia de direitos na execução da internação, coletando dados e relatando ao Juízo competente.

\section{CONCLUSÃO}

Intervir no atual cenário socioeducativo é uma atividade delicada, mais ainda quando esta desenvolve-se por meio do monitoramento de uma política pública no que diz respeito à possíveis violações aos direitos humanos. Dessa forma, o trabalho do "Direitos Humanos na Prática" progride com potencial para entender como ocorre, na prática, a execução das medidas socioeducativas de internação, verificando se há conformidade com o que é estabelecido pela Lei $n^{\circ} 12.594$ (Lei do SINASE) e pelo Estatuto da Criança e do Adolescente (ECA) ao fazer o monitoramento pontual de aspectos percebidos durante a atuação, além da produção acadêmica que traz transparência e o envio de relatórios para a Vara da Infância e Juventude. Assim, acredita-se que a discussão estabelecida no corpo deste trabalho alcançou o objetivo geral traçado, depreendendo a relevância que há em entender o papel e, consequentemente, a importância do projeto de extensão "Direitos Humanos na Prática" no monitoramento de garantias de adolescentes em medida socioeducativa de internação no CEDUC/Mossoró ao contribuir, direta e/ou indiretamente, com os órgãos que possuem essas funções institucionais de garantias de direitos dos adolescentes.

\section{REFERÊNCIAS BIBLIOGRÁFICAS}

BRASIL. Constituição (1988). Constituição da República Federativa do Brasil. Brasília, DF: Senado Federal: Centro Gráfico, 1988

BRASIL. Lei federal n 8069, de 13 de julho de 1990. Estatuto da Criança e do Adolescente. Brasília, DF: Senado Federal, 2016.

Lei n 12.594, de 18 de Janeiro de 2012. Brasília, DF: Congresso Nacional.

CASTRO, Ana Luiza de Souza; GUARESCHI, Pedrinho. Da privação da dignidade social à privação da liberdade individual. Psicologia \& Sociedade, Porto Alegre, v. 20, n. 2, p.200-207, Ago 2008. Disponível em: < http://www.scielo.br/scielo.php?script=sci_arttext\&pid=S010271822008000200007\&lng=en\&nrm=iso >.Acesso em: 29. mai. 2018.

DALLARI, Dalmo de Abreu. O que é participação política. Tatuapé: Brasiliense, 1983.

DECLARAÇÃO UNIVERSAL DOS DIREITOS HUMANOS, ONU, 1948. 
FÓRUM Permanente das ONGS de Defesa dos Direitos da Criança e do Adolescente do Ceará. Monitoramento do sistema socioeducativo: diagnóstico da privação de liberdade de adolescentes no Ceará. Fortaleza, 2011. Disponível em: <http://www.cedecaceara.org.br/wpcontent/uploads/2014/09/Monitoramento-do-sistema-socioeducativo-diagn\%C3\%B3stico-dapriva\%C3\%A7\%C3\%A3o-da-liberdade-de-adolescentes-no-Cear\%C3\%A1.pdf>. Acesso em: 27. dez. 2017.

GIUSTINA, E. F. D.; KOLODY, A.; MOSS, A.; POLI, J.. Extensão universitária e controle social: caminhos e possibilidades na construção de novas relações entre estado e sociedade civil. In: Anais... $6^{\circ}$ Seminário Nacional Estado e Políticas Sociais e $2^{\circ}$ Seminário de Direitos Humanos, 2014, Toledo, PR, 2014. Disponível em: <http://cac-php.unioeste.br/eventos/Anais/servicosocial/anais/TC_EXT_UNCNTRLE_SOC_CAMNHS_POSSIBS_CNSTR_NOV_RELS_ESTADO_SOC_ CIVIL.pdf>. Acesso em: 27. dez. 2017.

GOHN, Maria da Glória. Movimentos sociais na contemporaneidade. Revista Brasileira de Educação, Rio de Janeiro, v. 16, n. 47, p.333-361, maio/ago 2011. Trimestral.

MARTINELLI, Tiago. POLÍTICA NÃO CONTRIBUTIVA E DIREITOS SOCIAIS: O CASO DA ASSISTÊNCIA SOCIAL. Avaliação de Políticas Públicas, Porto Alegre, p.7-254, 2014.

MOREIRA, Ivana Aparecida Weissbach. Reflexões acerca dos direitos humanos e as medidas sócio-educativas. In: III Congresso Internacional de Pedagogia Social, 3, 2010, São Paulo. Disponível em: <http://www.proceedings.scielo.br/scielo.php?script=sci_ arttext\&pid=MSC0000000092010000100014\&lng=en\&nrm=abn>. Acesso em: 29. mai. 2018.

PATEMAN, Carole. Participação e teoria democrática. Rio de Janeiro: Paz e Terra, 1992.

RIO GRANDE DO NORTE. Portaria n. ${ }^{\circ}$ 270/15-GP, de 17 de Julho de 2015. Dispõe sobre o Regimento Interno das Unidades de Atendimento ao Adolescente em cumprimento de medida socioeducativa de Internação e Semiliberdade. Disponível em <http://adcon.rn.gov.br/ACERVO/ fundac/doc/DOC000000000083488.PDF>. Acesso em: 13 set. 2017. 